\title{
PARAMETER ESTIMATION AND PI CONTROL FOR A WATER COUPLED TANK SYSTEM
}

\author{
Mohamed G. Stohy ${ }^{1}$, Hossam S. Abbas ${ }^{2}$, Abou-Hashema M. El-Sayed ${ }^{3}$, and Ayat G. Abo El-maged ${ }^{4}$ \\ ${ }^{1,3}$ Minia University,Faculty of Engineering, El-Minia, Egypt; \\ e-mail:Mohamed.g@mu.edu.eg1, abouhashema@mu.edu,eg ${ }^{3}$. \\ ${ }^{2}$ Assiut University, Faculty of Engineering, Assiut, Egypt; \\ e-mail: hossam.abbas@aun.edu.eg². \\ ${ }^{4}$ El Minia High Institute for Engineering and Technology(MHIET), Egypt; \\ e-mail: Ayat.Abo_Elmaged@mhiet.edu.eg4.
}

\begin{abstract}
This paper presents an experimental application of parameter estimation and PI controller design for a state-coupled two-tank liquid level system. For this plant it is desired to provide a satisfactory performance for the control system. In the proposed approach a genetic algorithm optimization method is used to estimate the plant physical parameter values of the nonlinear system. The GA has been provided the system parameters as well as the real system performance is achieved. Then, a proportional-integral controller is designed to control the plant based on the linearized model and implemented experimentally. The experimental implementation provides a good performance and response.
\end{abstract}

Keywords-Parameter Estimation- Genetic Algorithm- Proportional Integral Control- Coupled Tanks System.

\section{Introduction}

In industry, the liquid level control system is used in various processes. Moreover, it is considered for filtration, boilers, petroleum and other several industries. For feedback control systems, typical actuators, such as pumps and motorized valves, are used together with level sensors such as pressure sensor and capacitance probe.

For the water tank systems, the proportional integral derivative (PID) controller is widely used in industrial liquid level control applications [1]. Applications of PID control is based on linearized models of system dynamics [2]. It has the ability to eliminate steady-state error through integral action. In addition, it can provide anticipation behavior by the derivative action. The popularity of the PID controller in the process industry come from its simple structure and easy tuning [5, 6].

In this work, a state-coupled two-tank liquid level system shown in Fig.1 is considered, which represents a single-input single-output (SISO) system and coupled state. However, to achieve a good control performance the physical parameter values of the plant should be estimated. The difficulty with the parameter estimation for this system is due to the nonlinear dependence on the parameters, the effects of the environmental changes on the plant and the measurement noise. In the present work, we consider the genetic algorithm(GA) optimization technique [7,8]for estimating (offline) the plant parameters. The GA is used to minimize the mean square error 
between the measured real-time signal and the simulated outputs of the nonlinear mathematical model of the plant, as a cost function.

Then, a PI controller is designed based on a linearized model of the state-coupled two-tank liquid level system corresponding to some intermediate operating point. The PI design is tuned heuristically. The experimental implementation of the controller demonstrates satisfactory results.
This paper is organized as follows: in section II, the nonlinear state-coupled two-tank liquid level system model and its linearization is described. Section III the parameter estimation algorithm and its results are given. Section IV is devoted for the PID control design. Section V presents the experimental results. Conclusion are given in the last section.

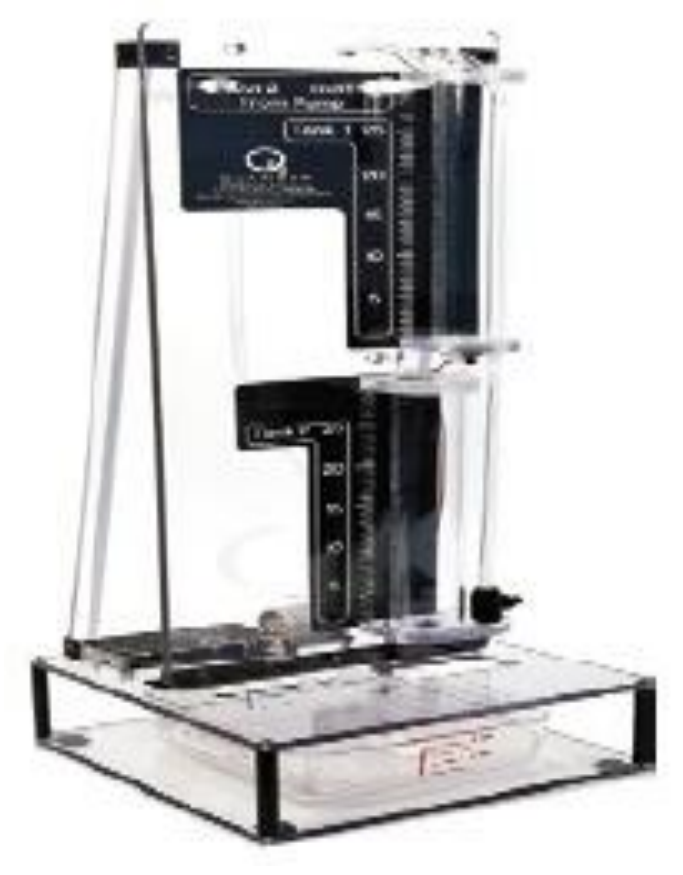

Fig. 1: Coupled tank liquid level system

\section{MODELING OF SYSTEM UNDER STUDY}

\section{A. Nonlinear Mathematical Model}

The schematic diagram of Fig.2 represents a two degree-of-freedom (2-DOF) state-coupled two-tank system. The system dynamic model for the liquid level in the two tanks are derived based on Fig.2 in the following manner.
The rate of change of the liquid level in each tank is given by

$$
\dot{L}_{l}(t)=\frac{1}{A_{t_{i}}}\left(F_{I N_{i}}-F_{\text {OUT }_{i}}\right) \text {. }
$$

where, $i=1,2, L_{i}, A_{t_{i}}, F_{I N_{i}}$ and $F_{O U T_{i}}$ are the liquid level (in $\mathrm{cm}$ ), cross-section area (in $\mathrm{cm}^{2}$ ), and inflow and outflow rates, respectively, for the $i^{\text {th }} \operatorname{tank}$ (in $\mathrm{cm}^{3} / \mathrm{s}$ ). The Volumatic inflow rate of tank 1 is directly 
proportional to the pump voltage, which is given by:

$F_{I N_{1}}=K_{p} V_{p}$.

where, $K_{p}$ and $V_{p}$ are the pump constant (in $\mathrm{cm}^{3} / \mathrm{Vs}$ ) and pump voltage, respectively. The outflow velocity (in $\mathrm{cm} / \mathrm{s}$ ) from the orifice at the bottom of each tank is computed using Bernoulli's Law

$V_{\text {OUT }_{i}}=\sqrt{2 g L_{i}(t)}$.

where, $g$ is the gravitational acceleration (in $\mathrm{cm} / \mathrm{s}^{2}$ ). Therefore, the outflow rate of each tank is given as

$F_{O U T_{i}}=A_{O U T_{i}} \sqrt{2 g L_{i}(t)}$. where, $A_{O U T_{i}}$ is the cross-section area of the outflow orifice at the bottom of $i^{\text {th }}$ tanks. The inflow of tank 2 is obtained by

$F_{O U T_{1}}=F_{I N_{2}}$.

Using mass balance principle and equations (1)- (5), the system dynamics equations can be rewritten as:

$\dot{L_{1}}(t)=\frac{1}{A_{t_{1}}}\left(K_{p} V_{p}(t)-A_{O U T_{1}} \sqrt{2 g L_{1}(t)}\right)$.

$\dot{L}_{2}(t)=\frac{A_{O U T_{1}}}{A_{t_{2}}} \sqrt{2 g L_{1}(t)}-\frac{A_{O U T_{2}}}{A_{t_{2}}} \sqrt{2 g L_{2}(t)}$

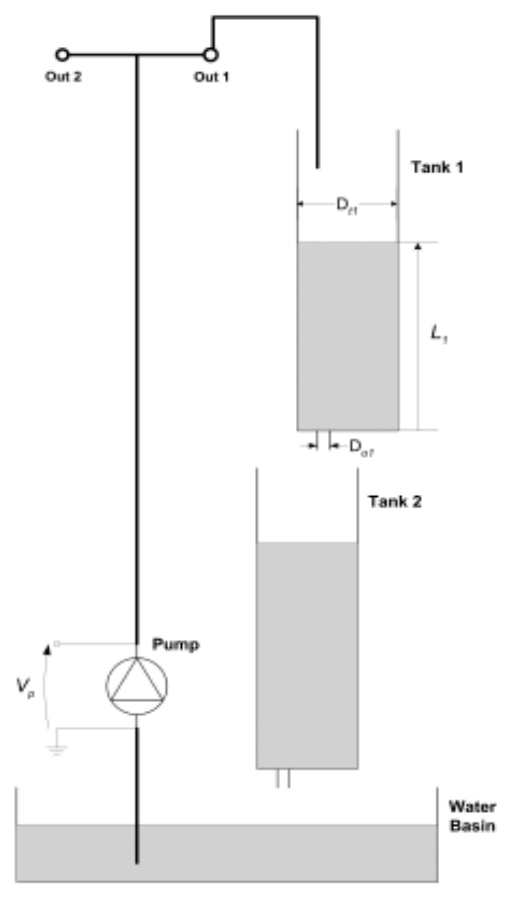

Fig. 2: Schematic of the state coupled two-tanks system.

\section{B. System Linearization Model}

The nonlinear mathematical model (6) and (7), can be linearized about a specific operating pump voltage and water levels for both tanks $\left(V_{p 0}, L_{10}\right.$, and $\left.L_{20}\right)$. The linearization process is considered for each tank separately.

The specific operating pump voltage and water levels for both tanks be denoted as $V_{p 1}$, $L_{11}, L_{21}$, then the pump voltage and water 
levels are changed as follows:

$$
\begin{aligned}
& V_{p}=V_{p 0}+V_{p 1}, \\
& L_{1}=L_{10}+L_{11}, \\
& L_{2}=L_{20}+L_{21} .
\end{aligned}
$$

At the equilibrium point, all time derivative terms equate zero. The pump voltage and the level of tank 1 are obtained corresponding to the specific operating point:

$V_{p 0}=\frac{A_{O U T_{1}} \sqrt{2 g L_{10}}}{K_{p}}$,

$$
\begin{aligned}
& {\left[\begin{array}{c}
\dot{L}_{11} \\
\dot{L}_{21}
\end{array}\right]=\left[\begin{array}{cc}
-\frac{A_{O U T_{1}} g \sqrt{2}}{2 A_{t_{1}} \sqrt{g L_{10}}} & 0 \\
\frac{A_{O U T_{1}} g \sqrt{2}}{A_{t_{1}} \sqrt{g L_{10}}} & -\frac{A_{\text {OUT }} g \sqrt{2}}{2 A_{t_{2}} \sqrt{g L_{20}}}
\end{array}\right]\left[\begin{array}{l}
L_{11} \\
L_{21}
\end{array}\right]+\left[\begin{array}{c}
\frac{K_{p}}{A_{t_{1}}} \\
0
\end{array}\right] V_{p 1},} \\
& y=\left[\begin{array}{ll}
0 & 1
\end{array}\right]\left[\begin{array}{l}
L_{11} \\
L_{21}
\end{array}\right]+0 .
\end{aligned}
$$

Tacking Laplace transform for both sides of equations (13) and (14), which the open loop system of coupled two tank shown in Fig.3 and the transfer function for each tank can be obtained as:

$$
\begin{aligned}
& G_{1}=\frac{L_{11}(s)}{V_{p_{1}}(s)}=\frac{K_{d c_{1} 1}}{\tau_{1} S+1}, \\
& G_{2}=\frac{L_{21}(s)}{L_{11}(s)}=\frac{K_{d c \_2}}{\tau_{2} S+1},
\end{aligned}
$$

Where,

$$
\begin{aligned}
& K_{d c_{-} 1}=\frac{K_{p} \sqrt{2} \sqrt{g L_{10}}}{A_{\text {OUT }} g}, \quad \tau_{1}=\frac{A_{t_{1}} \sqrt{2} \sqrt{g L_{10}}}{A_{\text {OUT } 1} g}, \\
& K_{d c_{-} 2}=\frac{A_{O U T_{1}} \sqrt{L_{20}}}{A_{O U T_{2}} \sqrt{L_{10}}}, \quad \text { and } \tau_{2}=\frac{A_{t_{2}} \sqrt{2} \sqrt{g L_{20}}}{A_{\text {OUT }} g} .
\end{aligned}
$$

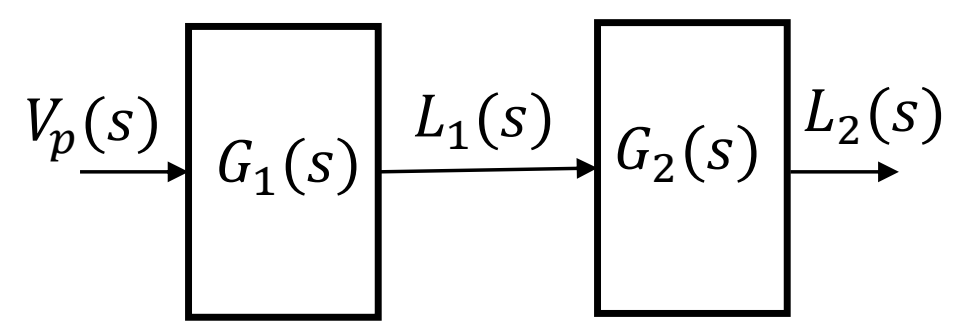

Fig. 3: The open-loop system of coupled-tank based on linearized model. 


\section{Parameter estimation baSed ON GENETIC ALGORITHM OPTIMIZATION}

The gray-box model for the nonlinear system is considered here, where the system structure is given by equations (6), (7) with the unknown parameter values. The genetic algorithm (GA) optimization for parameter estimation is considered [7] to estimate the unknown system parameters. Theses parameters are $K_{p}, A_{t_{1}}, A_{t_{2}}, A_{O U T_{1}}, A_{O U T_{2}}$, and $g$. The GA in this work, is proposed to minimize the mean square error between the measured real-time signal collected by Lab VIEW $^{T M}$ software and the simulated output signal of the nonlinear mathematical model of the plant. The MATLAB/SIMULINK software is used here to implement the genetic algorithm for the parameter estimation according to the flow chart shown inFig. 4.

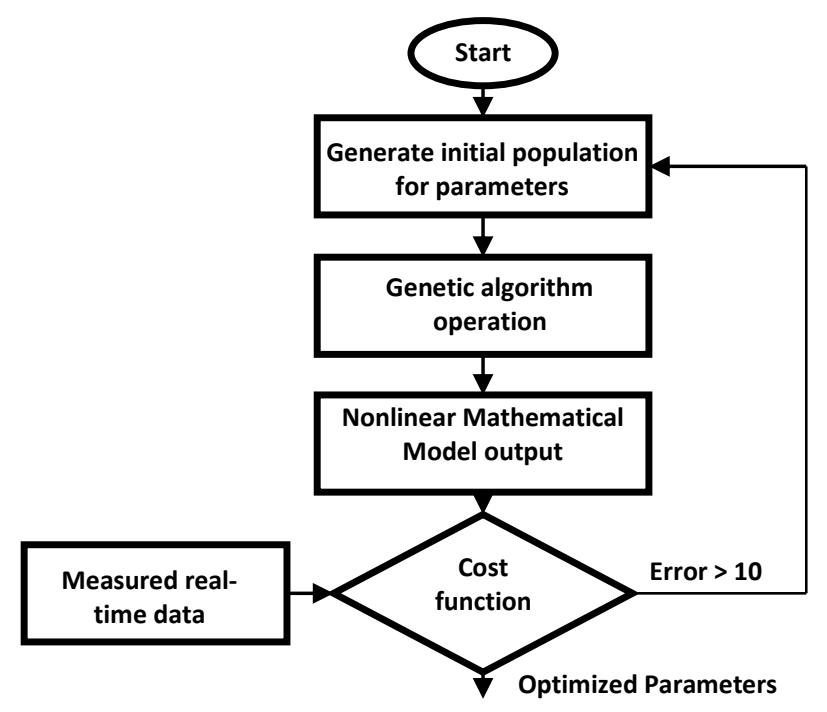

Fig.4 : The GA flow chart-based parameter estimation.

Table.1: GA operation parameters.

\begin{tabular}{|c|c|}
\hline GA parameters & Chosen value \\
\hline Crossover function & Heuristic \\
\hline Crossover fraction & 0.8 \\
\hline Population size & 100 \\
\hline Generation size & 60 \\
\hline Lower pounds & $\times 10^{-6}$ \\
\hline Upper bounds & $\times 20$ \\
\hline
\end{tabular}

The tuning parameters of the genetic algorithm including the crossover function, population size, generation size, crossover fraction, and the lower and upper bounds of each parameters are considered as a constrains in the model and are given in Table.1.

For applying the off-line parameter estimation, a set of input-output data should be generated from the system, which must represent the system behavior at the required range of system operation. A multivariable step signal between (0-22) volts shown in Fig. 5 is applied in real time to the system, then the output of the system states $L_{1}$ and $L_{2}$ are measured. 


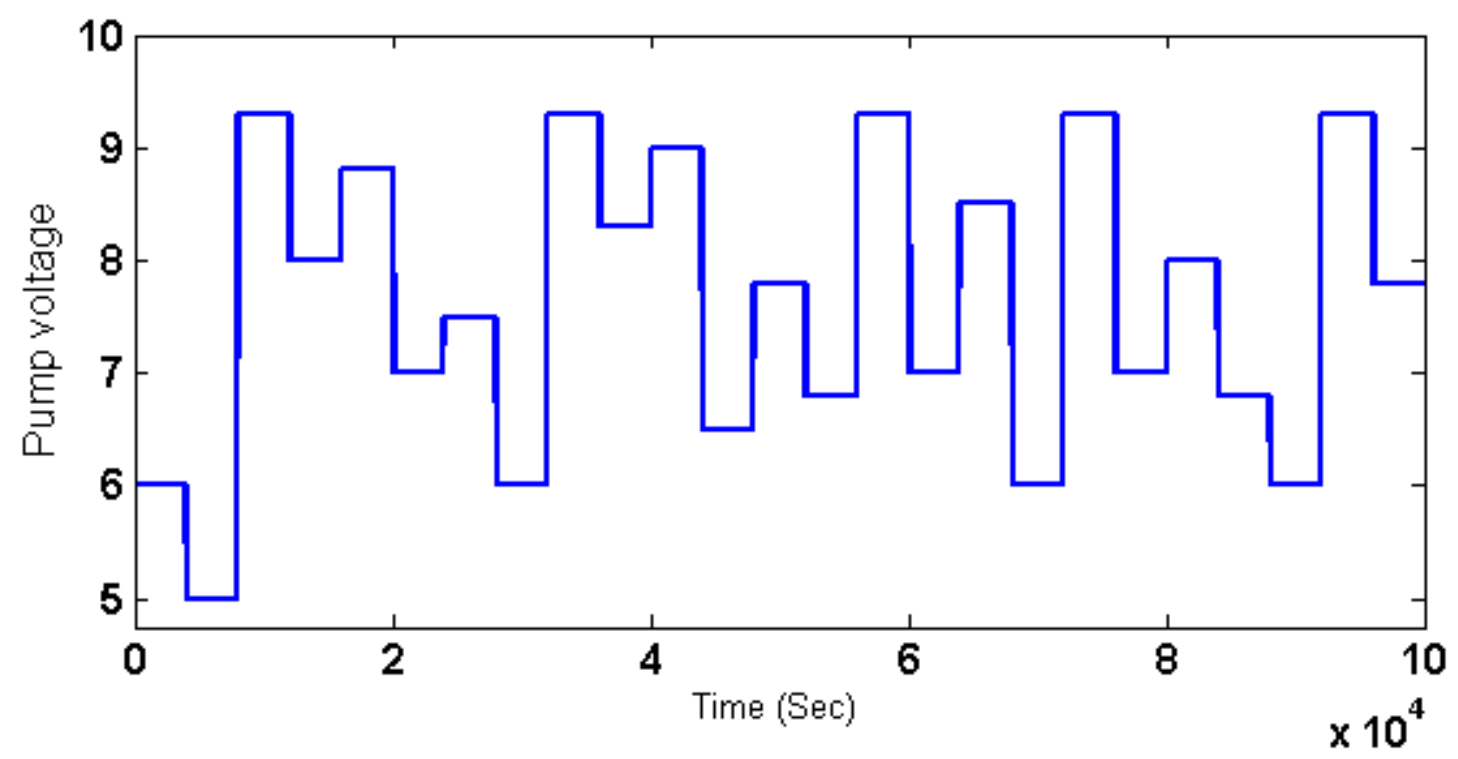

Fig.5 : The multivariable step input.

The best fit rate criterion $(B F R)$ given below is considered to validate the model,

$$
\begin{gathered}
B F R \%= \\
M A X\left(0.1-\frac{\operatorname{norm}\left(Y_{m}-Y_{S}\right)}{\operatorname{norm}\left(Y_{m}-\operatorname{mean}\left(Y_{s}\right)\right)}\right) \times 100 .
\end{gathered}
$$

where, $Y_{m}$ is the measured real-time data and $Y_{S}$ is the output simulated data.

In this estimation algorithm method, two cases are considered as follows:

Case.1: Estimating all the parameters $K_{p}$, $A_{t_{1}}, A_{t_{2}}, A_{O U T_{1}}, A_{O U T_{2}}$, and $g$. 
Case.2: Estimating the parameters $A_{t_{1}}, A_{t_{2}}$, $A_{O U T_{1}}, A_{\text {OUT }_{2}}$ and $K_{p}$, given $g=981 \mathrm{~cm} / \mathrm{s}^{2}$.
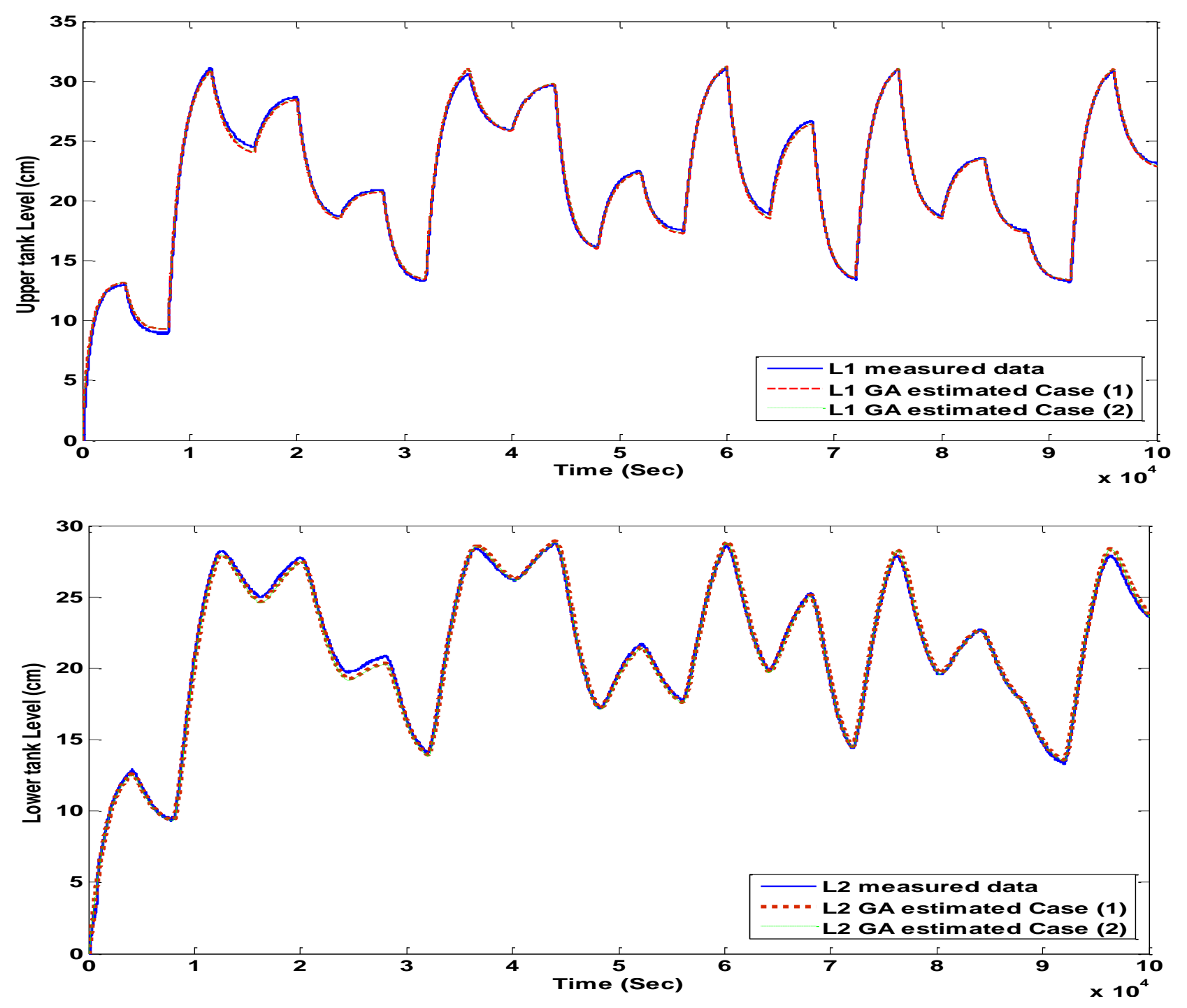

Fig. 6 : Measured and estimated upper tank level.

Fig.7 : Measured and estimated lower tank level.

Table. 2 shows the accuracy of the model with the identified parameters in terms of the best fit rate equation (19). Also, Figures. 6 and, 7 show a comparison between the measured and the simulated levels of both tanks for case (1) and (2). From these figures, it will be noted that the simulated values of levels are a good satisfactory with those measured values in both cases. Moreover, Table.3, shows the estimated parameters for the two cases. Note that, the estimated parameters in Table.3, do

not represent the corresponding physical values, however, the validation results in Fig.6 and 7 demonstrate that the mathematical model with such parameters is able to mimic the behavior of the real system. This can be justified as the used input signal excites the system in a limit operating range smaller than the whole operation of the system. Therefore, 
the obtained parameters are the best discretion of such data.

Table.2: Validation based on best fit rate.

\begin{tabular}{|c|c|c|}
\hline Case number & \%BFR of Upper tank & \%BFR of Lower tank \\
\hline Case. 1 & $95.9106 \%$ & $95.2327 \%$ \\
\hline Case. 2 & $96.0829 \%$ & $95.1898 \%$ \\
\hline
\end{tabular}

To reduce the noise level in the data, we have used a first-order low-pass filter to eliminate the noise from the measurement in the upper and lower tanks. The bandwidth of the filters is chosen larger than that one corresponding to the system dynamics.

Table.3: Estimated Parameters.

\begin{tabular}{|c|c|c|c|c|c|c|}
\hline Case number & \multicolumn{6}{|c|}{ Estimated Parameters } \\
\cline { 2 - 7 } & $A_{t_{1}}$ & $A_{t_{2}}$ & $A_{\text {OUT }_{1}}$ & $A_{\text {OUT }_{2}}$ & $K_{p}$ & $g$ \\
\hline Case.1 & 1.3629 & 1.4542 & 0.7107 & 0.7136 & 0.6501 & 1.1286 \\
\hline Case.2 & 4.1095 & 4.1476 & 0.0713 & 0.0718 & 1.9248 & 981 \\
\hline
\end{tabular}

\section{PI CONTROLLER DESIGN}

The PI controller is a linear control method used commonly in several applications [4]. the parallel form of the PI controller, three gains $K p$ and $K i$ are used in the decoupled branches of the PID controller.The PI control structure is given in the time domain by

$U_{c}(t)=K_{p} e(t)+K_{i} \int_{0}^{t} e(t) d(t)$.

and in the Laplace domain by

$U_{C}(s)=E(s)\left[K_{P}+\frac{K_{I}}{S}+K_{D} s\right]$.

where, $e=L_{2_{\text {Ref }}}-L_{2_{\text {measured }}}$ is the feedback error.

In our case, the PI controller is considered to control the nonlinear system as shown in Fig.6. The controller is designed to control the level tank $2\left(L_{2}\right)$ from the input $V_{p}$. Operating level considered here is $L_{10}=L_{20}=12 \mathrm{~cm}$ about which is derived from the linearized model. Then, the linearized model can be written in the form of transfer function as follow:

$G_{P}(s)=\frac{0 \cdot 0312}{s^{2}+0 \cdot 1723 s+0 \cdot 0074}$.

Then, the controller parameters $K_{p}$ and $K_{i}$ have been selected heuristically as 1.02 and 0.1 , respectively, which provide a good reference tracking with acceptable performance. 


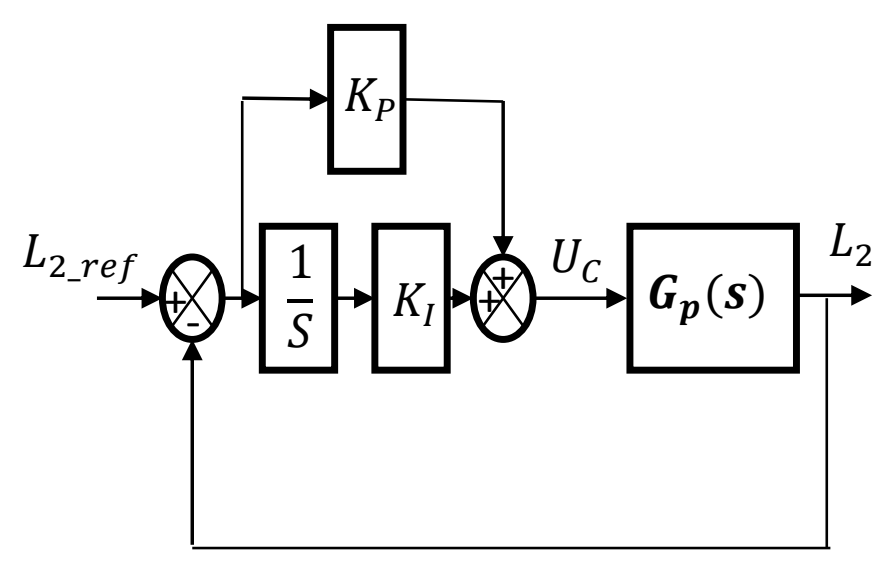

Fig. 8: Block diagram of the PI for the coupled -tanks system.

\section{EXPERIMENTAL RESULTS}

The PI controller shown in Fig.6is implemented experimentally on the statecoupled two-tank liquid level system [10] and [11]. The implemented controller system consists of: (1) a plastic two-tank module with height rang of (0-30) $\mathrm{cm}$ and uniform cross section area, which attached in the bottom of them with a pressure sensor and orifices, (2) liquid basin, (3) electromechanical gear pump rating of 22 volt, and hardware/ software for control. The hardware used to implement the proposed controller consists of: NI myRIO1900 controller, a Quanser terminal board for NI my RIO(QTB) as a data acquisition and a VoltPAQ-X1 power amplifier. The software environment for controller implementation is based on rapid control prototyping toolkit with Lab VIEW ${ }^{\text {TM }}$ software, as shown in Fig.7.

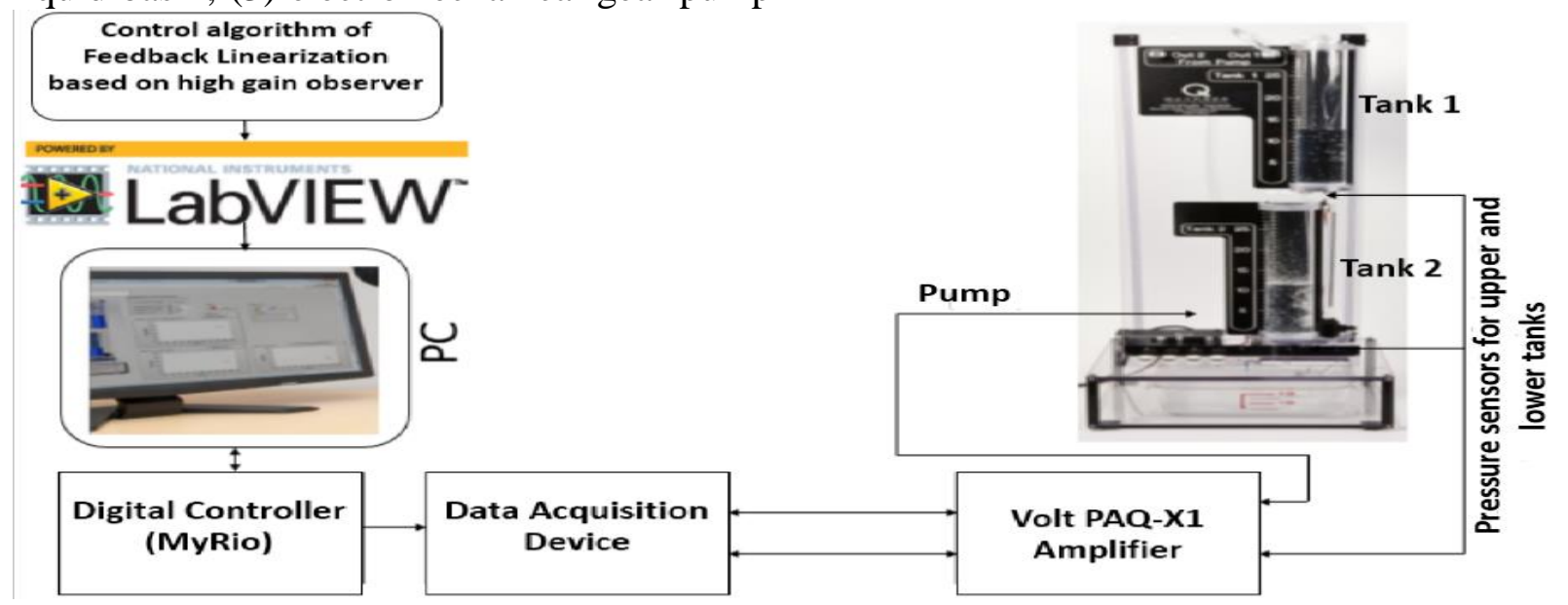

Fig. 9: Experimental setup block diagram. 
The tracking trajectory of the liquid level in the lower tank is shown in Fig.8and the level of the upper tank is given in Fig.9. Moreover, the feedback error is shown in Fig.11.From good tracking performance for a different level. Almost, a zero-feedback error as shown in Fig.11. Also, the response of uncontrolled upper tank level has a satisfactory result as shown in Fig.9.

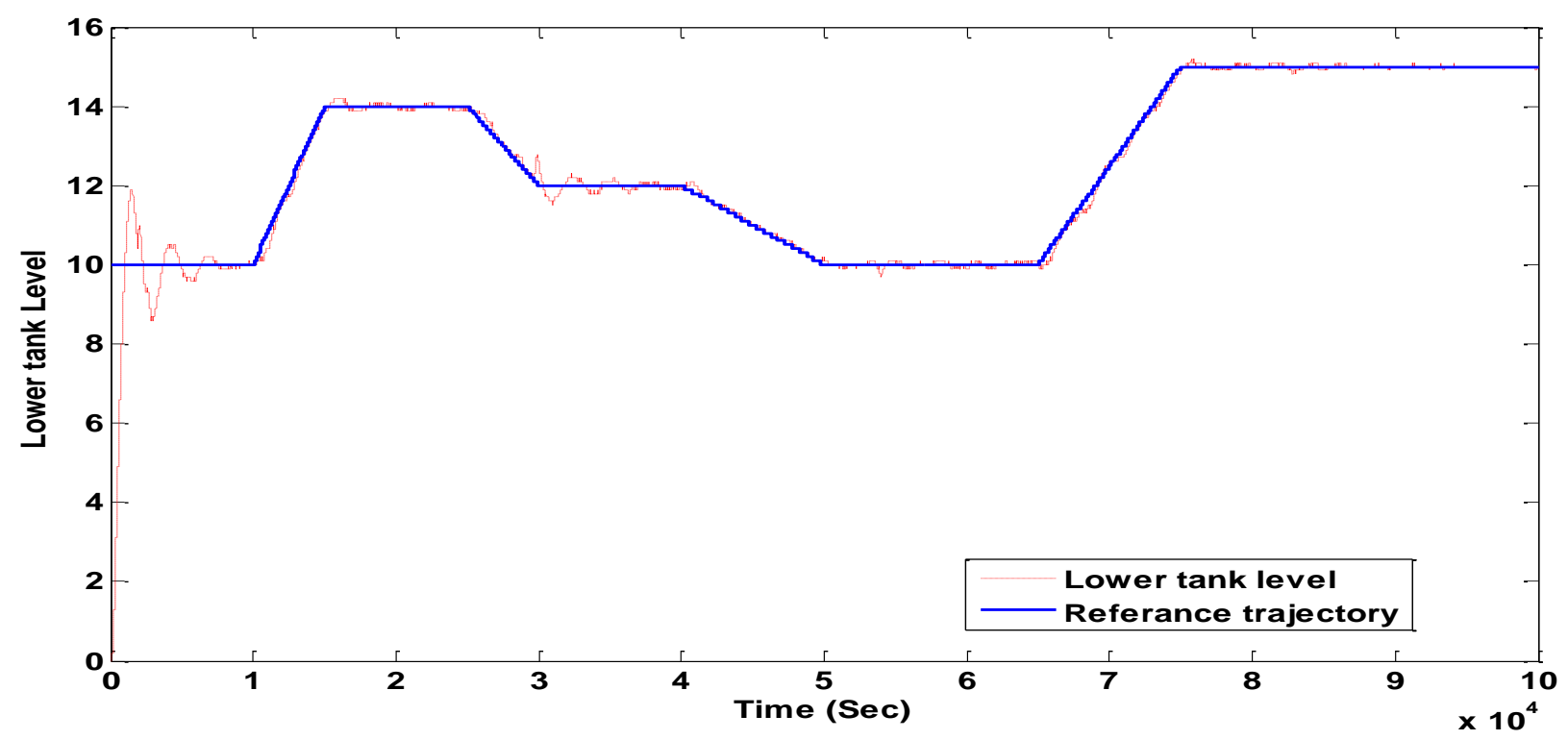

Fig.8, the response of the lower tank level has a

Fig.10 : PI control for lower tank level.

Fig. 11 : Upper tank level response.

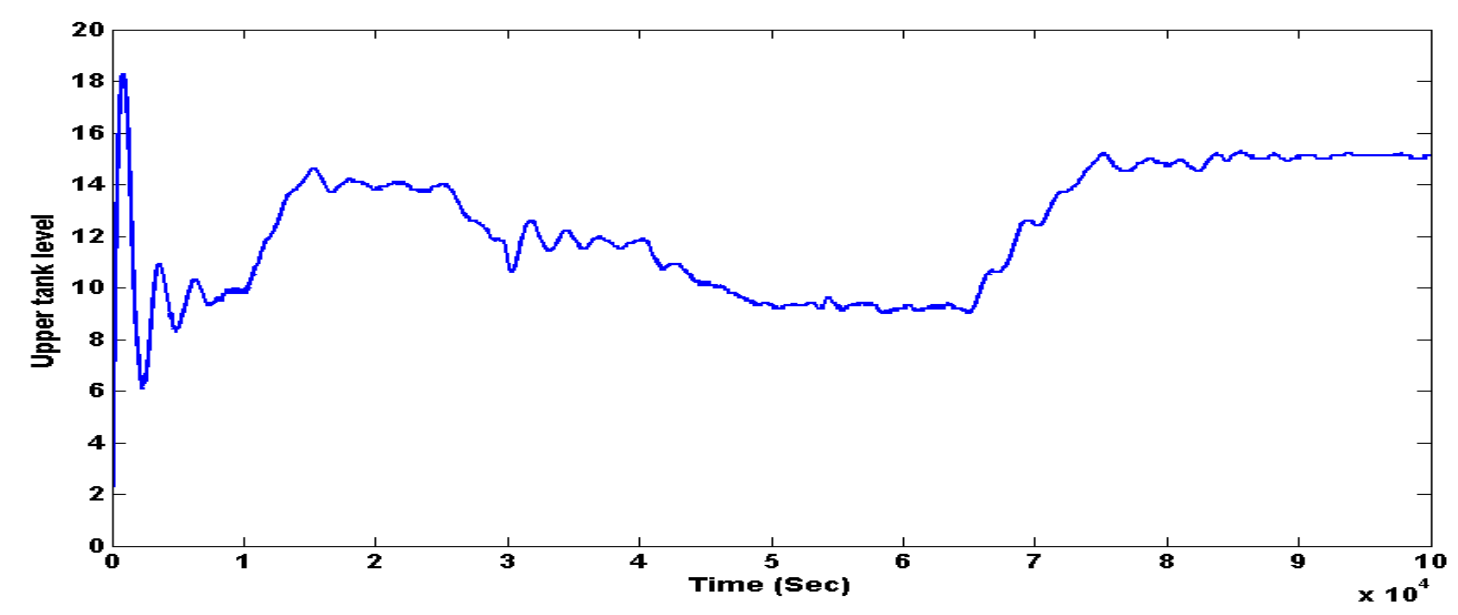




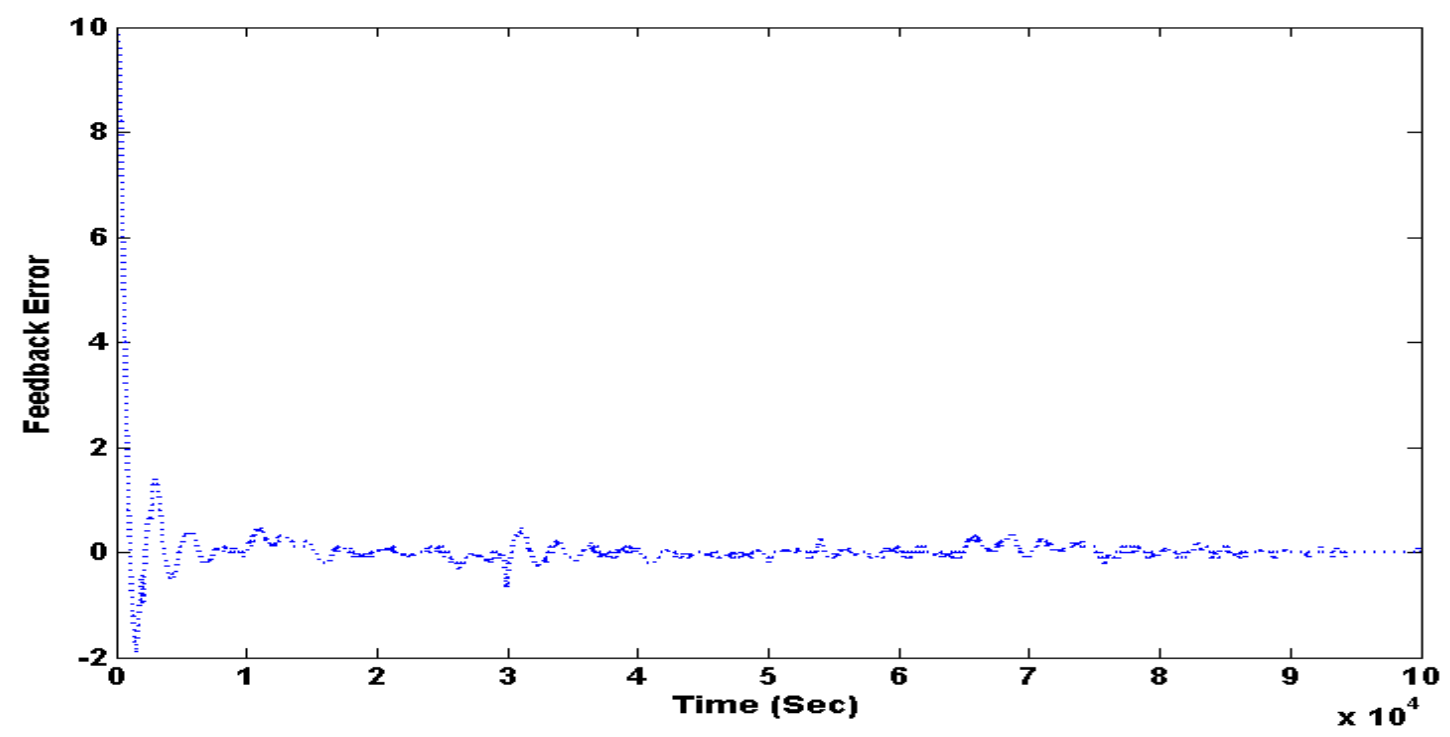

Fig. 12: The feedback error.

\section{CONCLUSION}

This paper presents a successful experimental application of parameter estimation and PI control for a state-coupled two-tank liquid level control system. The genetic algorithm optimization method has been considered here for the estimation of the all physical parameter values of the proposed nonlinear system. The genetic algorithm has provided the system parameters accurately, which reduced the mathematical model to mimic well the behavior of the real system. Also, the accuracy of the model with the estimated parameters is tested by using the BFR criterion. Then, a linear PI controller is designed based on a linearized model of the nonlinear system and implemented experimentally. This controller can provide a system stability and a good reference tracking with acceptable transient response and a steady-state response.

\section{REFERENCES}

[1] Mostafa.A. Fellani ， A.M.G., PID Controller design for two Tanks liquidlevel Control System using Matlab. International Journal of Application or Innovation in Engineering \& Management (IJAIEM), May 2015. 4(5): p. 5-10.

[2] Eker, J.M.a.J., Hybrid Control of a Double Tank System. IEEE International Conference on Control Applications. Hartford, CT, 1997: p.133-183.

[3] Elizabeth Rani T, S.I.J., Modelling and Design Aspects of PI Controller for Coupled Tank Process. International Journalof ComputerApplications, 2013. 2: p. 10-17.

[4] Surbhi Sharma, M.A., Kuldeepak Kaushik, Analysis-Of-Liquid-LevelControl-Of-Coupled-Tank-System-By-PiPd-Pid-Controller. INTERNATIONAL JOURNAL OF SCIENTIFIC \& 


\section{TECHNOLOGY RESEARCH,2015.}

4(11).

[5] Cominos, P. and N. Munro, PID controllers: recent tuning methods and design to specification. IEE Proceedings ControlTheory and Applications, 2002. 149(1):p. 46-53.

[6] Nitin Goyal, L.R., Controller Tuning of Coupled Tanks By Astrom \& Hagglund Using Matlab \& Simulation. International Journal of Research in Management, Science \& Technology, April2015. 3(2).

[7] Leehter Yao, W.A.S., Nonlinear Parameter Estimation Via the Genetic Algorithm. IEEE TRANSECTION ON SIGNAL PROCESSING APRIL 1994. 42(4)

[8] Asan Mohideen, K., et al., Real-coded Genetic Algorithm for system identification and tuning of a modified Model ReferenceAdaptiveController for a hybrid tank system. Applied Mathematical Modelling, 2013. 37(6): p. 3829-3847

[9] Wang, S. and X. Xu, Parameter estimation of internal thermal mass of building dynamic models using genetic algorithm. Energy Conversion and Management, 2006. 47(13-14): p. 19271941.

[10] Quanser Coupled-Tank, User manual.

[11] Quanser Coupled Tank-Quick Start Guide. 


\section{ملخص البحث}

تقدم هذه الورقة البحثية تطبيقا عمليا لتقدير المعماملات و تصميم متحكم تتاسبى تفاضلى نظام التحكم في مسوى السائل في الخزاناتالمقترنة. بالنسبة لهذه العملية، المطلوب توفير أداء مُرضٍ لنظام التحكم. فى هذا النهج المقترح تمم استخدام الخوازرمية الجينية لتقدير قيم المعاملات الفزيائية للنظام الاخطى. الخوارزمية الجينية وفرت معاملات للنظام النى تحقق اداء النظام الحقيقى. بعد ذاللك، تم تصميم متحكم تتاسبى تفاضلى للتحكم في النظام استتادًا إلى النموذج الخطي وتطبيقه تجريبًا. يوفر التنفيذ التجريبي أداءً واستجابةً جيدًا. 